\title{
The Reality of Practicing the Decision-Making Process in Public Schools for Boys in the Directorate of Education Amman Brigade
}

\author{
Prof. Adnan Abdessalam Adaileh \\ Professor of Educational Administration, \\ Al-Balqa Applied University, \\ Princess Alia University College, \\ Amman, Jordan
}

\author{
Dr. Jamal Fawaz Al-Omari \\ Associate Professor of Educational Administration, \\ Al-Balqa Applied University, \\ Princess Rahma University College, \\ Salt, Jordan
}

Doi: 10.36941/jesr-2020-0049

\begin{abstract}
This study aimed to identify the reality of decision-making practice in public schools for boys in the Directorate of Education Amman Brigade. To achieve the goal of the study the researchers used the descriptive survey method, and the questionnaire was applied to a study sample consisted of (62) principals of public schools for boys for the academic year 2018/2019. The study results showed that, the degree of school principals practicing decision-making in public schools came with a moderate degree. The most frequently practiced phrases were: I care about decisions that make the school a better environment for the educational process, the decisions I make are subject to the school external environment conditions, and I specify the goals of the decision before issuing it. Where the highest obstacles facing principals in decisionmaking in public schools are the large burdens placed on the principal, the lack of participation in decisionmaking, the scarcity of training courses for school decision-making processes, and the lack of powers granted to the principal in decision-making. The study recommended that teachers must participate with the principal in the school decision-making process. When selecting school principal, it is preferable to be a holder of a master's or a doctorate in the field of educational administration, to hold special programs for preparing school principals according to the requirements of school accreditation.
\end{abstract}

Keywords: school principals, decision-making, government boy's schools, the Directorate of Education Amman Brigade

\section{Introduction}

Today the globe witnessed several developments, changes, and challenges in all aspects of life, especially in the education field, that resulted from knowledge development which made the world today as a small village. On the other hand, the developments in information technology and the emergence of the knowledge economy made administrative institutions depend more on cognitive 
and intellectual capabilities than physical effort, the manager must be aware of the implications of this fact when administrating his institution. Therefore, the school administration has received great attention because of the significant role it plays in the success of the educational process. The past years witnessed a new trend in school administration that changed the traditional methods of administrating the school affairs, such as maintaining the school system and discipline, ensuring the proper functioning of the school, limiting the absence of students and working on improving their knowledge acquisition, but the role of the school administration today lies in creating good educational opportunities for learners (Bilbeisi, 2007).

According to Ahmed (2003), if schools want successfully to fulfill their roles, they need leadership cadres that have the competencies, think creatively, influence the behavior of their staff and spread a spirit of cooperation among them as well as honest competition. They can also play various roles such as persuading them to implement the school's visions and mission to bring about the required changes, increasing their interest in teamwork, enabling them to face future challenges and contributing in making school decisions to bring about the required changes and development, in a compatible way with the cognitive and technological changes and developments.

Generally speaking, school success is based on the success of the school principal in performing his work properly, and it also greatly depends on the extent of the sound decisions he takes concerning his work as the decision-making process is important because of the different changes occurred in the educational process. It is known that, decision-making is the core of the administrative process and the axis around which all its aspects revolve (Atwi, 2014). The Decisionmaking process is fundamental in the field of administration, as it is considered the engine of human resources efforts and activity. It includes all the administrative functions and elements that the success of the administrative process based on when making decisions or achieving the desired goals .

Undoubtedly, if we look at the practicing decision-making in educational institutions, we realize that it is of great importance, more serious and far-reaching. Therefore, the principal must enjoy what is so-called, the administrative sense in carrying out the administrative tasks, he must fully believe in the necessity of achieving the goals of the institution as well as having the courage to take the required decisions. That is having the audacity and the wits in confronting situations and resolving conflicts with a considerable decision. Administrative decisions are considered one of the main functions of any administration sector, which are: planning, organizing, directing and controlling. Simon considered it a synonym of the administration because he sees that administration exercises making decisions, and making decisions is an act of the administration (Hariri, 2016).

\section{Literature Review}

Through reviewing the studies that dealt with the same subject of this study, we realize that some of these studies differ in terms of the variables they examined such as the relationship between two variables such as job satisfaction and creativity, motivation and crisis management. The results of the Ghetto study (2019) showed that the level of participation in decision-making in public education schools came with a moderate degree in the schools of the Royal Commission in Yanbu.

Al-Muharraq (2018) conducted a study that aimed at investigating the effects of the decisionmaking process in public education schools in Al-Zulfi Governorate. The results of the study showed that there were significant obstacles in the decision-making process where the most important of which are the lack of information, weak professional development programs and the lack of incentives for participants in the decision-making process. Al-Khudari (2017) conducted a study aimed to identify the effectiveness of decision-making among high school principals the Gaza Strip and its relationship to crisis management. The results of the study indicated that the effectiveness of decision-making among high school principals in the Gaza Strip came with a moderate degree.

Shaheen (2015) study, tagged with the degree of education directors' practice of transparency in decision-making, indicated that education directors make decisions with a high degree of transparency and the level of performance of school principals was significant in the field of decision- 
making. In 2012, Moodley conducted a case study aimed to identify how to exercise leadership and decision-making through school structures. The results of the study showed that there were several methods of decision-making inside the school and that there were some challenges facing joint decision-making in schools. Kertzer ( 2012) focused on how to understand and make school principals use data in the decision-making process. The results of the study showed that the process of using and analyzing data is an integral part of the process of improving education that depends on the decision-making process and that effective use of data improves the decision taken and increases the participation of teachers in the protection of decision-making.

Al-Juhani (2010) performed a study aimed to identify the reality of decision-making practices in managing school crises from principals' perspectives in Yanbu Governorate and to reveal the impact of some variables on school principals' estimates of the method used to make decisions during school crises. The study used the questionnaire which was applied to all the principals of general education schools in the Education Department in Yanbu Governorate, whose number is (97) principals. The study found that school principals practice decision-making methods in managing school crises in varying degrees, where the degree of practicing decision-making methods ranged from a very high degree to high degree in these dimensions; case study, personal and intuitive judgment, studies of opinions and suggestions, experimentation, and probability theory.

This study differs from some of the previous studies in the terms of its procedures and the used tools such as the study of Ghetto (2019), Shaheen (2018) and Al-Khudari's study (2017), and it dealt with an important topic; which are the problems that hinder decision-making process among school principals. And that the current study focused on the administrative decision-making process for school principals in the Amman First Education Directorate and the constraints they face. The researchers found that there were some problems facing school principals in the educational decision-making process, therefore they examined these problems to identify and to overcome them.

\subsection{The study problem and its questions}

The success of educational institutions, including the school, based on the ability of the leader to make the right decision based on sound foundations and under specific information. Precisely, the administrative decision is to choose a specific alternative solution from several different alternatives, and this is considered a correct perception of the truth of the decision. This opinion indicates the ease and simplicity of the decision-making process, where the fact is different, this process is a devilishly complex process because the administrative activity is only a series of decision-making. (Hariri, 2016). And the success of the principal in the decision-making process has positive and negative repercussions on the work of teachers in the school. Teachers prefer the principal who has a strong personality in decision-making, and they do not prefer the principal who makes weak decisions. Accordingly, the researchers found it necessary to examine the reality of decision-making practice and the obstacles facing principals.

Some previous studies in the field of decision-making in educational administrative work indicated that many aspects affect the decision-making process, such as the study of Ghetto (2019), Shaheen (2018) and Al-Khudari (2017). Where other studies revealed that decisions are affected by the personal circumstances of the decision-makers, such as experience and feeling, and some depend on the availability of appropriate information to make the soundest decision. This revealed the reason for the differences between the decision-makers in the process of decision-making, which accordingly reflected in the type of taken decisions (Al-Ayta, 2014). However, the decision-making process must base on specialized and accurate information to be considered while making decision. This is confirmed by the study of Kitzer (2012), Moodley (2012). It is also the most prominent obstacle that the schools face when making the decision and that was brought about by the study sample who indicated in their responses to the lack of enough information.

According to the researchers' experience and through what they noticed from the reality of the decision-making process at the school level that must be realized by the principals of public 
education schools in the Directorate of Education Amman Brigade and that how some problems may affect the process of decision-making among school administrators in the Directorate of Education Amman Brigade. Therefore, the study problem was determined by answering the following two questions:

1. What is the reality of practicing the decision-making process in public schools for boys in the Directorate of Education Amman Brigade?

2. What are the obstacles to decision-making faced by the directors of public education schools in the Directorate of Education Amman Brigade?

\subsection{The importance of studying}

The importance of the current study is clear in the following:

Theoretical importance:The scientific importance of the subject and the extent of its contribution to enriching the educational and scientific field for researchers and scholars in the field of educational decision-making.

Practical importance:

- This study is useful for educators in identifying the obstacles of decision-making, to work to take the necessary and enough measures to overcome them.

- This study is useful for revealing the reality of the decision-making process at the executive level in the school.

- This study is useful for those in charge of education to identify the means to improve the decision-making process and work to strengthen it.

- This study may contribute to improving the performance of school principals, through considering the results and recommendations of this study.

\subsection{Objectives of the study}

This study aims to: identify the reality of the decision-making process among the principals of general education schools in the Directorate of Education Amman Brigade, and to identify the obstacles that hinder the effectiveness of decision-making process among the principals in the Directorate of Education Amman Brigade.

\subsection{The limits of the study}

The current study is limited to the following:

I. The objective limits: The study was limited to identifying the problems that hinder the effectiveness of decision-making among the principals of general education schools in the Directorate of Education Amman Brigade.

II. Human limits: The study was applied to the principals of public schools for boys in the Directorate of Education Amman Brigade. Variables, qualification, practical and managerial experience were excluded from the study results.

III. Spatial limits: The study was conducted on public schools for boys in the Directorate of Education Amman Brigade.

IV. Time limits: The study was conducted in the second semester of the academic year 2018/2019.

\subsection{The study Terms}

Efficacy: is defined as the ability to achieve maximum results using available resources, the best possible use. It is also defined as the ability to make the decision achieving the desired goals and its 
success depends on the ability and efficiency of the teaching staff. (Al-Sharif, 2018)

Decision-making: Hariri (2014) defined it as a conscious choice that is selected among the available alternatives in a particular situation, or it is the process of choosing between alternative solutions to confront a specific problem and choosing the best solution from them." It is the choice that meets the approval and preference of the manager or the decision-maker, after subjecting the situation to analysis and diagnosis, and determining what behaviors to do to benefit the situation, and what must be left. (Al-Jamila, 2017) .Procedurally it is defined as "choosing an alternative from several alternatives to achieve specific goals". School principal: Al-Taani (2005) defined school principal as "the person appointed by the Ministry of Education in the school to organize all its facilities, supervise the teachers in technical and administrative terms, and work to conduct the school day effectively and efficiently" and is responsible for managing the school.

\section{Methodology}

The study followed the descriptive survey method.

\subsection{Study population}

It consisted of (62) principals of the basic and secondary schools in the Directorate of Education Amman Brigade according to the statistics issued by the Directorate of Education in Amman for the first academic year 2019 .

Table 1: Number of principals in the Directorate of Education Amman Brigade

\begin{tabular}{|l|c|c|}
\hline \multirow{2}{*}{ Schools } & \multicolumn{2}{|c|}{ No. } \\
\cline { 2 - 3 } & Basic & Secondary \\
\hline Principals & 42 & 20 \\
\hline Total & \multicolumn{2}{|c|}{62} \\
\hline
\end{tabular}

Table 2: Distribution of the study sample in schools according to the educational qualification, practical experience in the field of educational management

\begin{tabular}{|l|l|c|c|}
\hline Variable & Number & Percent \\
\hline \multirow{2}{*}{ Qualification } & Undergraduate & 39 & $63 \%$ \\
\cline { 2 - 4 } & Master & 23 & $37 \%$ \\
\hline \multirow{2}{*}{ Experience } & $6-10$ yrs. & 25 & $60 \%$ \\
\cline { 2 - 4 } & $11-15$ yrs. & 37 & $40 \%$ \\
\hline \multicolumn{2}{|l|}{ Total } & 62 & $100 \%$ \\
\hline
\end{tabular}

\subsection{Study tool}

To achieve the objectives of the study, the researchers benefited from the previous studies such as the study of Al-Ghamdi (2010) and Sharif (2018) to build the paragraphs of the questionnaire that was applied to the study sample. The tool was certified during its initial design with several steps until it became usable in the current study.

The questionnaire consisted of two parts:

- The first part: the primary data, which includes the educational stage, the academic qualification, years of experience in the educational administration field.

- The second part: consisted of two areas, the first area includes (35) items of the questionnaire that examine the reality of decision-making practice with the principals of public schools in the Directorate of Education Amman Brigade. Where the second area 
contains (20) items examining the obstacles that hinder the effectiveness of decisionmaking among the principals of public schools. The 3-point Likert scale was used with the ranks: high, moderate, and low.

\subsection{The reliability of the study tool}

To confirm the consistency of the tool, the questionnaire correlation coefficient was calculated statistically, using the Test-Retest method by applying the questionnaire to $(8$ school principals who were randomly chosen from outside the main study sample, then the test was repeated with two weeks period between the two tests. To confirm the reliability the correlation coefficient with its calculation of the full value according to the Pearson Correlation Coefficient was used. The value of the questionnaire correlation coefficient was (o.91) for the administrative decision-making process for principals of basic and secondary schools in public schools in the Directorate of Education Amman Brigade which is considered an acceptable value for the reliability purposes.

\subsection{Study procedures}

After ensuring the validity of study tool (the questionnaire) it was applied by the following procedures:

- Obtaining the statistics of boys' schools in the Directorate of Education Amman Brigade from the Education Directorate to count the members of the study sample.

- The researchers cooperated and distributed the questionnaires to the study sample members of (62) school principals.

- And then they collected the questionnaires to obtain clear answers, and it took five weeks for the distribution and retrieved.

\subsection{Statistical methods}

The following statistical methods were used: frequency, percentage, and arithmetic mean, standard deviation and (Test and Pearson Correlation Coefficient) test to confirm the reliability of the questionnaire. After the information was entered into the computer and reviewed, the study data was analyzed using the SPSS, where specific scores for each of the answer fields were given the following numerical values: high (3), moderate (2), low (1). Certain codes were given to the primary information for the members of study sample. The analysis included basic information related to the study.

\section{Discussion}

This section presents the discussion of the results of the first question

1: What is the reality of practicing the decision-making process in public schools for boys in the Directorate of Education Amman Brigade?

To answer this question, we used mean averages and standard deviations for the responses of the study sample as shown in Table (3).

Table 3: The arithmetic means and the standard deviation on the reality of practicing the decisionmaking process in government schools for boys in the Directorate of Education Amman Brigade:

\begin{tabular}{|c|c|c|c|c|}
\hline No. & Items & Means & SD & Rank \\
\hline 1 & $\begin{array}{l}\text { I am concerned with decisions regarding making the school a better environment for the } \\
\text { educational process }\end{array}$ & 2.89 & .51 & high \\
\hline 2 & The decisions I made are subject to the external environment conditions of the school & 2.89 & .65 & high \\
\hline 3 & I determine the purpose of the decision before making it. & 2.87 & .69 & high \\
\hline
\end{tabular}




\begin{tabular}{|c|c|c|c|c|}
\hline No. & Items & Means & SD & Rank \\
\hline 4 & I prefer the decisions which is made through the formed committees & 2.88 & .69 & high \\
\hline 5 & A limited power is granted to me in terms of making-decisions. & 2.87 & .72 & high \\
\hline 6 & I am interested in implementing the decisions of the Parents and Teachers Council. & 2.86 & .75 & high \\
\hline 7 & The prevailing pattern of educational administration does not allow me to make decisions. & 2.78 & .71 & high \\
\hline 8 & I am interested in students' participation in making decisions in issues concern them. & 2.69 & .47 & high \\
\hline 9 & I feel comfortable when implementing collective decisions. & 2.67 & .56 & high \\
\hline 10 & I involve parents in decisions that is related to their children. & 2.61 & .83 & high \\
\hline 11 & I prefer individual decisions. & 2.51 & .53 & high \\
\hline 12 & I made decisions without referring to school personnel. & 2.47 & .63 & high \\
\hline 13 & I trust decisions that are made collectively. & 2.41 & .52 & high \\
\hline 14 & I care about the humanitarian aspect of my decisions. & 2.39 & .59 & high \\
\hline 15 & I involve the school vice-principal in making some decisions. & 2.36 & .57 & high \\
\hline 16 & My decisions are subject to the decisions of the Ministry. & 2.35 & .51 & high \\
\hline 17 & I objectively make decisions. & 2.35 & .54 & high \\
\hline 18 & $\begin{array}{l}\text { I follow up on the implementation of the decisions to find out the extent of their achievement in } \\
\text { the field. }\end{array}$ & 2.33 & .59 & high \\
\hline 19 & I take the right decision at the right time. & 2.31 & .48 & high \\
\hline 20 & I make decisions in the light of administrative and educational information in the field of a school. & 2.28 & .57 & high \\
\hline 21 & I am interested in decisions related to innovation in educational aspects. & 2.27 & .60 & high \\
\hline 22 & I revoke my decision when it proves invalid. & 2.26 & .76 & high \\
\hline 23 & I take advantage of the outcome of decisions in developing my administrative work. & 2.25 & .63 & high \\
\hline 24 & I follow the decisions made by teachers in aspects related to their work and monitored. & 2.23 & .63 & high \\
\hline 25 & I am interested in identifying the staff s acceptance of the decisions I made. & 2.22 & .64 & high \\
\hline 26 & I put multiple alternatives when making decision. & 2.19 & .55 & high \\
\hline 27 & I use the appropriate means of communication to announce the decisions he made. & 2.18 & .66 & high \\
\hline 28 & I am interested in assessing the results of decisions based on their suitability to actual needs. & 2.17 & .63 & high \\
\hline 29 & I am interested in implementing the decisions of who and teacher's council. & 2.86 & .75 & high \\
\hline 30 & I allow teachers to participate in making decisions that concern them. & 2.15 & .65 & high \\
\hline 31 & I make appropriate awareness about the decisions before I start implementing them. & 2.14 & .64 & high \\
\hline 32 & I cancel the decision, which I do not trust its results. & 2.13 & .69 & high \\
\hline 33 & No decision is issued except with the attendance of all parties related to the decision. & 2.12 & .67 & high \\
\hline 34 & I allow my colleagues to express their views & 2.11 & .73 & moderate \\
\hline 35 & I consult the teachers in decision-making & 1.49 & .79 & low \\
\hline 36 & I ensure discussing matters with the teachers & 1.46 & .71 & low \\
\hline Tota & & 2.40 & 0.61 & moderate \\
\hline
\end{tabular}

Table (3) indicates that the total means of the estimates of the sample members on the reality of decision-making practice in public schools for boys in the Directorate of Education Amman Brigade was (2.40) with a (moderate) degree. This result is consistent with the findings of both Ghetto (2019), Al Muhrej (2018) in terms of the lack of effective decision-making among school principals and it is consistent with Al-Khudari (2017), Al-Juhani (2010). Where it differed with the results of the Sharif ( 2018), Shaheen (2015). To show the responses of the study sample to all questionnaire items were arranged in descending order according to the higher average. Item (1) which stated that "I am concerned with decisions regarding making the school a better environment for the educational process" came in the first rank with the mean (2.87), SD (0.51) and a (high) rank. Where the item stipulated that "The decisions I made are subject to the external environment conditions of the school" came in the second place with the mean (2.79) the SD (0.47) and a high rank. The third rank were for the item (3) that stated "I determine the purpose of the decision before making it" with the mean (2.76) and SD (0.56) and it also rank high.

Actually, all the first ten items came with a (high) degree. While the following (14) items came with a (moderate) degree. Item (35) and (36) that stated, "I consult the teachers in decision-making" and "I ensure discussing matters with the teachers" ranked last with the averages (1.95), (1.86) respectively and with a (low) degree. The results of the second question: What are the obstacles to decision-making faced by the directors of public education schools in the Directorate of Education Amman Brigade?

To answer this question, the mean averages and standard deviations for the responses of the 
study sample were calculated as shown in Table (4).

Table 4: The means and SD for the responses of the study sample

\begin{tabular}{|c|c|c|c|c|}
\hline No. & phrases & mean & SD & Rank \\
\hline 1 & The large burdens placed on the school principal & 2.93 & .67 & high \\
\hline 2 & Literal adherence to regulations and instructions & 2.89 & .67 & high \\
\hline 3 & Lack of training courses related to school decision-making processes. & 2.79 & .63 & high \\
\hline 4 & Lack of participants' experience in decision making. & 2.75 & .69 & high \\
\hline 5 & The lack of powers granted to the school principal in school decision-making. & 2.69 & .89 & high \\
\hline 6 & $\begin{array}{l}\text { Those in charge of collecting and arranging information are not eligible, in addition to weak } \\
\text { information systems. }\end{array}$ & 2.65 & .69 & high \\
\hline 7 & Weak desire of workers to assume their responsibilities & 2.49 & .78 & high \\
\hline 8 & The leader reduces giving employees the opportunity to participate in decision making. & 2.90 & .67 & high \\
\hline 9 & The leader strictly following the rules and regulations. & 2.89 & .67 & high \\
\hline 10 & The working environment does not help in large performance appraisal systems. & 2.79 & .63 & high \\
\hline 11 & The leader does not encourage workers to make decisions without resorting to him. & 2.75 & 0.69 & high \\
\hline 12 & The leader's appreciation of the workers' achievements is low. & 2.69 & .89 & \\
\hline 13 & Lack of support and capabilities to complete the work. & 2.45 & .84 & high \\
\hline 14 & There is a weak staff willingness to take on more responsibilities. & 2.39 & .82 & high \\
\hline 15 & The leader refrains from the decision-making teams' style. & 2.27 & .95 & moderate \\
\hline 16 & There is a limited delegation of the manager's authority. & 2.24 & .91 & high \\
\hline 17 & The work environment does not help in solving problems facing teachers. & 2.20 & .93 & moderate \\
\hline 18 & There is a lack of data & 2.17 & .89 & moderate \\
\hline 19 & Poor mutual trust between the principal and the teachers. & 2.10 & .84 & moderate \\
\hline 20 & The principal hesitated to choose alternatives. & 2.09 & .78 & moderate \\
\hline & Overall average & 2.41 & .78 & moderate \\
\hline
\end{tabular}

Table (4) shows that the total average for the study sample responses came with a (moderate) degree of (2.41) and SD (o.78), where there were different obstacles facing the principals of public schools in the Director of Education when making decisions the most prominent obstacles were: the huge burdens that principals hold, Literal adherence to regulations and instructions, the lack of training courses for school decision-making processes, and the lack of participants' experience in decisionmaking. The least occurring obstacles are the lack of data availability, poor mutual trust between the principals and teachers, and the principal's hesitation to choose alternatives. The results of this question are consistent with the findings of Al-Khudari (2017) study and Kertzer (2012) study in terms of the need for information and evidence for decision-making among school principals and the results of Moodley (2012) which showed that there were significant challenges in decision-making among school principals and that failure to grant sufficient powers to principals is one of the main obstacles to deciding between schools.

\section{Conclusion}

The main results of this study are summarized as follows:

- The degree of school principals practicing decision-making in public schools came with a moderate degree. The most frequently practiced phrases were: I care about decisions related to making the school a better environment for the educational process, the decisions I make are subject to the external environment conditions of the school, and I determine the purpose of the decision before making it.

- The highest obstacles facing principals in decision-making in public schools are the large burdens placed on the principal, the lack of participation in decision-making, the scarcity of training courses related to school decision-making processes, and the lack of powers granted to the principal in school decision-making. 


\section{Recommendations}

Considering the results of the study, the researchers recommend the following:

- Involving teachers in decision making in school-related issues.

- Increasing principals' training courses that develop their competencies in making sound decisions.

- Reducing the responsibilities of the principals by providing integrated administrative staff in public schools.

- Selecting school principals according to objective conditions, the most important of which are the academic qualification, practical experience, the number of training courses they attended, and to allow the young to hold an administrative role in school administration.

- Holding intensive training courses for principals in coordination with the colleges of education to raise the level of administrative and institutional work and introduce them to the latest concepts in the art of school administration.

- The Ministry of Education must reconsider the methods and the administrative systems of the principals through training courses compatible with the latest methods in school decision-making skills.

- Creating a school committee responsible for the school decision-making process supervised by the principal, vice-principal, and teachers to discuss any new decisions.

- Stipulating the necessity to assign school principals who hold masters or Ph.D. especially in the field of educational administration, preparing a special program for school principals according to school accreditation requirements.

\section{References}

Abu Al-Ela, S. (2003). The process of making and making educational decisions in school administration. Scientific Journal, Aswan College of Education, South Valley University. Volume 19, First Issue.

Ahmed, A, I. (2003). School administration at the beginning of the twenty-first century. Cairo: Dar Al-Fikr Al-Arabi.

Atwi, J, E. (2014). School administration concepts, 1st floor, Amman Culture House.

Ghetto, A. (2019).Decision-Making for School Leaders in Yanbu, Journal of the College of Education, Ismailia University, Egypt.

Al-Hariri, R. (2016) Decision Making Skills in Educational Leadership, Dar Al-Fekr Publishing Oman.

Al-Jamila, Z. (2017). The concept of decision-making, Journal of the College of Economics and Management, University of Babylon, Iraq.

Al-Juhani, A, M. (2010). Decision-making methods in managing school crises from the viewpoint of school principals in Yanbu Governorate. (Unpublished Master Thesis). Jeddah: King Abdulaziz University.

Kertzer.S. (2012). Data-Focused Decision-making: One School's Journey. Dissertation submitted Doctor of Education in Educational Leadership and Policy Studies, Virginia Polytechnic Institute, USA

Al-Khudari, N. (2017). Effectiveness of decision-making among high school principals, including by managing crises in the Gaza Strip. (Unpublished Master Thesis). The Islamic University, Gaza, Palestine.

Al-Ma'aytah, A. (2015) .School Administration between theory and practice, Amman Hamed Publishing, Amman

Moofley, R. (2012) .Decision Making as an Activity of School Leadership: A case study. (Unpublished Master Thesis)., school of education development, university of KwaZulu, Natal.

Shaheen, A. (2015) The degree of education managers in the Gaza Strip governorates exercising transparency in decision-making. (Unpublished Master Thesis) Islamic University, Gaza.

Al-Sharif, A. (2018).Degree of the effectiveness of decision-making by managers of private schools in the Gaza Strip. Unpublished Master Thesis, Islamic University, Palestine.

Al-Taani, H, A. (2005). Sources of work pressure for the principals of public schools in Karak from their point of view. Damascus University Journal, Volume (21),No. 2.

Embarrassed, Abdul Karim. (2018). The decision-making process in public education schools in Al-Zulfi Governorate. Journal of Scientific Research in Education, 19, Part 12, Faculty of Education, Ain Shams University, Egypt. 